\title{
Uso das vibrantes na aquisição do português como língua estrangeira por nativos americanos e espanhóis: implicações ao ensino
}

\author{
Use of vibrant in the acquisition of Portuguese as a foreign language by \\ native American and Spanish speakers: implications for teaching \\ Alessandra Dutra \\ Universidade Tecnológica Federal do Paraná - Londrina - Paraná - Brasil \\ $\diamond$
}

\begin{abstract}
Resumo: Seguindo os pressupostos teóricos da Sociolinguística Laboviana, o estudo propõe analisar o uso das vibrantes na aquisição do português como língua estrangeira por nativos americanos e espanhóis. Para isso, selecionamos os tipos de pesquisa bibliográfica, de campo e analítica e dividimos a fala de 11 nativos americanos e 11 espanhóis em estilos que vão dos informais até os mais formais. Os resultados mostraram que o contexto em que os informantes usam um fonema na língua nativa motiva o seu uso na aprendizagem do português. A aquisição dos fonemas do português é mais célere entre os informantes mais jovens e o uso de estruturas da língua materna dos informantes são mais frequentes em estilos de fala informais.
\end{abstract}

Palavras-chave: Variação fonética; Português para estrangeiros; Fatores linguísticos e extralinguísticos

\begin{abstract}
Based on the theoretical postulations of Labov's Sociolinguistics, this study proposes to analyze the use of vibrant in the acquisition of the Portuguese as a foreign language by native Americans and Spanish speakers. For this purpose, it was selected types of bibliographical, field and analytics researches and, the speech from 11 American and 11 Spanish native speakers were divided in styles, which passes through informal to ones that are more formal. The results showed that the context, in which the informants use a phoneme in their native language, motivates its usage in learning Portuguese. The acquisition of phonemes of Portuguese is more rapid among the younger informants while the informant's mother tongue structure usage is more common in informal speech styles.
\end{abstract}

Keywords: Phonetics variation; Portuguese to foreign speakers; Linguistic and extra linguistics aspects

\section{Introdução}

Ao pensarmos na aquisição de segunda língua, o que nos vem à mente é como o indivíduo adquire uma língua diferente de sua língua materna, e quais são os fatores que interferem e podem causar facilidade ou dificuldade nessa aquisição. Ao entenderem o que ocorre quando os aprendizes adquirem estruturas diferentes das de sua língua nativa, os professores podem escolher a abordagem e o método que visem resultados satisfatórios na aprendizagem de língua estrangeira. Nesse sentido, buscamos, nesta pesquisa, analisar o uso das vibrantes encontrados na fala de americanos e espanhóis falantes nativos do inglês e espanhol aprendizes do português. Procuramos, também, refletir sobre a formação do professor de português como língua estrangeira e oferecer contribuições para a área de português para falantes de outras línguas (PPFOL).

A realização desta pesquisa deu-se pelo interesse em estudar a variação que existe na fala de aprendizes do português, pois a maioria dos trabalhos referentes ao ensino de línguas estrangeiras está relacionada às dificuldades de aprendizagem, tais como: possíveis interferências, avaliação, métodos e abordagens, entre outros. Nossa pesquisa norteia-se pelos pressupostos teórico-metodológicos da Sociolinguística, sob a pers- 
pectiva da Teoria da Variação, proposta por Labov (1972) para quantificar os fatores que atuam na variação e/ou na mudança de línguas.

O propósito deste estudo, no entanto, não é verificar mudança e sim a variação presente no português falado por americanos e espanhóis. Acreditamos que as dificuldades dos aprendizes se apresentam como fenômenos de variação na língua alvo e aparecem com maior ou menor frequência, de acordo com a influência que terão os fatores linguísticos - contextos fônicos e estruturas da sílaba e do vocábulo - e extralinguísticos - idade e estilos de uso da linguagem (desde a fala espontânea a estilos mais formais).

\section{Aquisição de segunda língua: a contribuição da sociolinguística}

Larsen-Freeman (1993) faz uma retrospectiva na área de aquisição de segunda língua e mostra como houve ampliação do foco da pesquisa. Segundo ela, há mais de quarenta teorias sobre aquisição de segunda língua e, dentre as muitas teorias presentes, há aquelas que relacionam a identidade ao aprendizado de línguas, aquelas que valorizam o contexto social do aprendiz, as que entendem a aquisição como um resultado de uma capacidade inata do indivíduo para a aprendizagem, entre outras.

O estudo da relação entre sociedade e linguagem não é atual, ele partiu na década de 60 com o surgimento do termo sociolinguística. Segundo Fernandez (1998), a Sociolinguística tem e terá muito que decidir em relação ao ensino de línguas, pois discorrer sobre atitudes, registros, variedades sociais e culturais no ensino de línguas é fazer referência aos conceitos que a Sociolinguística defende há muitos anos. $\mathrm{O}$ autor ainda refere que é inegável que a área, com suas múltiplas manifestações, tem contribuído para a difusão e valorização de uma determinada forma de ver a língua. Além do mais, a Sociolinguística vem reforçar a prioridade que se dá à língua oral antes que à escrita. Os métodos de ensino de línguas mais recentes veem a necessidade de incorporar variáveis sociais às investigações aplicadas que utilizam os informantes como fonte provedora de dados.

Fernandez (1998, p.320) também afirma que os melhores resultados no ensino de línguas obtêm-se quando o contexto linguístico dos cursos prevê as necessidades funcionais dos alunos, ou seja, a necessidade de trabalhar a língua em seu contexto social. A existência da variação não pode ser ignorada nem no ensino da língua materna nem no ensino de línguas estrangeiras, pois os aspectos sociolinguísticos das línguas são muito relevantes no nível teórico de ensino.

Assim, a vinculação da Sociolinguística com a aquisição de segunda língua produz-se em diferentes níveis: o social, em que se determina a política de ensino de línguas dentro de uma comunidade, o nível cultural em que a língua é instrumento de relação entre o indivíduo e o ambiente, o nível comunicativo, em que a língua é um mecanismo básico de interação, e o nível linguístico, em que a língua se vê afetada por variantes de natureza extralinguísticas.

\section{Procedimentos metodológicos}

Os tipos de pesquisa utilizados neste estudo são: descritiva bibliográfica, de campo e analítica. Primeiramente, foram selecionados dois grupos de informantes de duas nacionalidades diferentes. O primeiro deles, constituído por 11 americanos e o segundo, por 11 informantes espanhóis. Eles residem na região Norte do Paraná, nas cidades de Cambé, Rolândia, Londrina e Ibiporã.

Com vista à elaboração do instrumento de coleta de dados, adotamos a metodologia empregada nas pesquisas sociolinguísticas de base laboviana, ou seja, o questionário possibilitou que depreendêssemos desde a fala espontânea até a fala em contextos mais formais. Segundo Labov (1972, p. 79-81), podem-se coletar estilos diferentes de fala dependendo do contexto da entrevista. $\mathrm{O}$ autor divide os contextos em A, B, C e D. O contexto A é o estilo de fala casual/espontâneo. Para esse contexto, o autor apresenta o estilo de fala coletado por meio de conversa com uma terceira pessoa, a fala sem ser em resposta direta possibilita ao informante discorrer sem ser interrompido, como apresentar rimas de infância, falar sobre costumes e narrar sobre temas como perigo de morte. No contexto B, depreende-se o estilo de fala cuidadosa, através de entrevista dirigida, que ocorre normalmente quando o informante está respondendo a perguntas que são formalmente reconhecidas como parte da entrevista. No contexto C, o autor apresenta o estilo de leitura, no qual o informante se concentra em leitura de texto(s). O contexto D envolve a leitura de uma lista de palavras.

O autor afirma que o instrumento de coleta de dados, elaborado e dividido dessa maneira, permite ao pesquisador coletar os mesmos fenômenos em vários estilos de linguagem. A nossa pesquisa toma como referencial a proposta de coleta de dados de Labov (1972, p. 79-81): estilo espontâneo, estilo de fala dirigida, de leitura de texto e listas de palavras. As entrevistas com os nativos americanos foram realizadas em uma escola de idiomas localizada na cidade de Londrina-PR, local de trabalho desses informantes. As entrevistas com os espanhóis foram realizadas em suas próprias residências. As datas e horários das entrevistas foram estipulados pelos informantes. Cada entrevista durou aproximadamente 30 minutos. 
Buscamos analisar, em nossa pesquisa, fenômenos de variação fonética na fala dos grupos de americanos e espanhóis e, para isso, realizamos uma transcrição fonética ampla, ${ }^{1}$ sem levar em conta determinadas nuanças fonéticas. Na transcrição fonética dos fenômenos estudados, transportamos os dados diretamente para o computador e realizamos a transcrição dos dados com o auxílio de um programa chamado speech analyzer. As transcrições de fala dos informantes mais jovens levaram de meia hora a quarenta minutos. Com os informantes mais velhos, as transcrições levavam de duas a três horas, totalizando, aproximadamente, 49 horas de transcrições.

\subsection{Apresentação e análise dos dados}

Nosso corpus constitui-se de um total de 4.973 ocorrências das vibrantes. Consideramos, em nossa análise, os contextos linguísticos em que as variantes ocorrem (posição na estrutura da sílaba, posição no interior do vocábulo e contexto fônico precedente e/ou seguinte) e os fatores extralinguísticos - gênero, faixa etária e estilos de linguagem (que nos permitissem depreender desde a fala espontânea até a fala em contextos mais formais) em que os dados foram coletados - que pressupomos estarem favorecendo o uso das variantes típicas da língua portuguesa ou determinando a permanência de variantes próprias da língua materna (inglês e espanhol) dos informantes.

\subsubsection{O uso das vibrantes}

Em vista dos vários matizes fonéticos encontrados nas vibrantes, adotamos, para a análise da fala dos americanos e espanhóis, uma classificação que dê conta do uso variável das vibrantes, atentando apenas para as realizações que resultam em diferenças marcadas no português do grupo pesquisado, se comparada sua pronúncia com a de falantes nativos do português do Brasil. Desse modo, consideramos, em nossa análise, a fricativa glotal desvozeada, o tepe alveolar vozeado simples (o tepe), a retroflexa alveolar vozeada e a vibrante alveolar vozeada.

Os contextos para análise da fala dos americanos e espanhóis são: posição pré-vocálica em início de palavra, em grupos consonantais, entre vogais e em final de sílaba. Das 2.577 ocorrências das vibrantes na fala dos americanos: 1.346 (52,23\%) são de vibrante simples, 910 $(35,31 \%)$ de vibrante retroflexa, e $321(12,46 \%)$ da glotal.

\footnotetext{
Denomina-se transcrição fonética ampla aquela transcrição que explicita apenas os aspectos que não sejam condicionados por contexto ou características específicas da língua ou dialeto: como kilo ['kilu] - em oposição a kilo ['k'1 $1^{\mathrm{w}} \mathrm{v}$, que é uma transcrição fonética restrita (CRISTÓFARO-SILVA, 2001, p. 36).
}

Não houve ocorrência da vibrante alveolar. Das 2.396 ocorrências das vibrantes coletadas com os informantes espanhóis, $240(10,02 \%)$ são de vibrantes alveolar retroflexa, $1.530(63,85 \%)$ são da vibrante simples, 157 $(6,55 \%)$ são da glotal e $469(19,58 \%)$ são da vibrante alveolar.

Ao todo, analisamos 4.973 ocorrências de vibrantes na fala dos dois grupos. Esses percentuais, no entanto, não refletem o uso que o grupo de falantes americanos e espanhóis aprendizes do português fazem das vibrantes; pois essas variantes, por um lado, não ocorrem em todos os contextos fônicos e estruturas silábicas - por exemplo, na fala dos americanos, em grupos consonantais aparecem [r] e [ı], mas não [h], prato ['pratu] ['pıatu]. Por outro lado, as variantes ocorrem, no corpus, em contexto que, na fala de nativos do português brasileiro, dificilmente aparecem - por exemplo, roda ['roda] ['ı⿰da].

\subsubsection{As vibrantes em posição pré-vocálica em início de palavra}

Em posição pré-vocálica, em início de vocábulo realizam-se, no português do grupo de americanos, as variantes: retroflexa, rosa ['.ıza]; tepe, redondo [re'đodv]; e posterior, rato ['hatu]. Há, nessa estrutura silábica, predomínio da glotal, $50 \%$ - que é a articulação própria da língua portuguesa -, seguida da retroflexa, 31,08\%, e, por último, do tepe, 18,92\% (cf. Tab. 1). Essa variação no uso das vibrantes ocorre apenas com os informantes da terceira faixa etária, pois com os mais jovens não há variação nesse contexto. No grupo espanhol, o maior número de ocorrências nesse contexto foi da vibrante alveolar (62,74\%), seguida da glotal $(35,85 \%)$ e do tepe $(1,41 \%)$. Não houve ocorrência da vibrante alveolar retroflexa.

Tabela 1. Uso das vibrantes, pelos informantes americanos e espanhóis em posição pré-vocálica em início de vocábulo

\begin{tabular}{ccccc}
\hline & \multicolumn{2}{c}{ Americanos } & \multicolumn{2}{c}{ Espanhóis } \\
\cline { 2 - 5 } & no & $\%$ & no & $\%$ \\
\hline 1 & 23 & 31,08 & 0 & 0,00 \\
$r$ & 14 & 18,92 & 3 & 1,41 \\
$\mathrm{~h}$ & 37 & 50,00 & 76 & 35,85 \\
$\hat{r}$ & 0 & 0,00 & 133 & 62,74 \\
Total & 74 & 100 & 212 & 100 \\
\hline
\end{tabular}

Os resultados apresentados na Tabela 1 indicam que, assim como alguns falantes nativos do português apresentarão dificuldades em realizar a vibrante retroflexa no inglês ou a vibrante alveolar no espanhol em posição pré-vocálica em início de palavra, os americanos e 
espanhóis aprendizes do português demonstram ser influenciados pela estrutura de sua língua materna ao realizar a retroflexa, o tepe ou a vibrante alveolar nesse contexto. É importante ressaltar, no entanto, que o uso variável das vibrantes em posição pré-vocálica em início de vocábulo - rosa ['.ıza] ['roza] ['hoza] se dá só entre falantes com mais idade - terceira faixa etária do grupo de americanos e segunda e terceira dos falantes espanhóis. $\mathrm{O}$ conhecimento de que, na língua portuguesa, apenas as articulações posteriores ocorrem nesse contexto, parece já ter sido assimilado pelas faixas etárias mais jovens, que realizam expeditamente a variante glotal desvozeada $/ \mathrm{h} /$

Os resultados mostrados na Tabela 2 indicam que os informantes americanos das faixas etárias mais avançadas produziram as três variantes: a glotal desvozeada, $(50 \%)$, a retroflexa, $(31,08 \%)$, e o tepe $(18,92 \%)$. Ainda que o predomínio seja da glotal nesse contexto, o uso da retroflexa é bastante relevante. Na fala dos informantes espanhóis da segunda faixa etária depreendemos as variantes tepe com índice de $(4,62 \%)$ e a vibrante alveolar com $(67,69 \%)$; na fala dos da terceira faixa etária ocorre, além da posterior com índice de $(6,32 \%)$, a vibrante alveolar com $(93,68 \%)$.

A interferência da língua materna no português falado pelos inquiridos nativos espanhóis torna-se mais evidente, ao depreendermos em nossa pesquisa, a vibrante linguo-alveolar, visto que no norte-paranaense a vibrante que predomina, nesse contexto, é a alveolar retroflexa. Os altos índices de uso do tepe pelos espanhóis demonstraram uma variação, uma maneira de suavizar o som da vibrante alveolar nesse contexto, apesar de sua rara ocorrência não só na região onde residem os informantes desta pesquisa, mas no Brasil, de modo geral. A esse respeito concordamos com Broselow (1984) ao afirmar que, muitas vezes, quando a língua-alvo apresenta estruturas silábicas que não ocorrem na língua nativa, os falantes podem forçar as estruturas da língua-alvo a se conformarem às restrições da língua nativa.

Acreditamos que os informantes mais velhos não percebem que essas consoantes dificilmente ocorrem no português nesse contexto. Já os informantes mais jovens apresentam mais facilidade na aprendizagem de estruturas diferentes da língua materna pois vemos que eles não apresentam variação no uso das vibrantes em posição pré-vocálica em início de vocábulo (cf. Tab. 2). A esse respeito concordamos com Confortin (2001) quando ela afirma que o maior apego à língua materna está entre os sujeitos mais velhos para quem a língua vem carregada de afetividade. Os mais jovens não desprezam a língua materna, mas integram-se a uma sociedade cujos valores são variados e os dialetos nada mais são que um falar sem importância linguístico-cultural.
Tabela 2. Uso das vibrantes, pelos informantes americanos e espanhóis das três faixas etárias, em posição pré-vocálica em início de vocábulo

\begin{tabular}{|c|c|c|c|c|c|c|}
\hline \multicolumn{7}{|c|}{ Americanos } \\
\hline & \multicolumn{2}{|c|}{ 1a Faixa etária } & \multicolumn{2}{|c|}{ 2ª Faixa etária } & \multicolumn{2}{|c|}{ 3a faixa etária } \\
\hline & no & $\%$ & no & $\%$ & no & $\%$ \\
\hline$\lambda$ & 0 & 0,00 & 0 & 0,00 & 23 & 31,08 \\
\hline$r$ & 0 & 0,00 & 0 & 0,00 & 14 & 18,92 \\
\hline $\mathrm{h}$ & 51 & 100 & 46 & 100 & 37 & 50,00 \\
\hline$\hat{\mathrm{r}}$ & 0 & 0,00 & 0 & 0,00 & 0 & 0,00 \\
\hline Total & 51 & 100 & 46 & 100 & 74 & 100 \\
\hline \multicolumn{7}{|c|}{ Espanhóis } \\
\hline & \multicolumn{2}{|c|}{ 1a Faixa etária } & \multicolumn{2}{|c|}{ 2a Faixa etária } & \multicolumn{2}{|c|}{ 3a faixa etária } \\
\hline & no & $\%$ & no & $\%$ & no & $\%$ \\
\hline 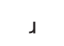 & 0 & 0,00 & 0 & 0,00 & 0 & 0,00 \\
\hline$r$ & 0 & 0,00 & 3 & 4,62 & 0 & 0,00 \\
\hline $\mathrm{h}$ & 52 & 100 & 18 & 27,69 & 6 & 6,32 \\
\hline$\hat{r}$ & 0 & 0,00 & 44 & 67,69 & 89 & 93,68 \\
\hline Total & 52 & 100 & 65 & 100 & 95 & 100 \\
\hline
\end{tabular}

Os estilos de linguagem correspondentes às situações enunciativas em que coletamos os dados também se mostram relevantes em relação ao uso das vibrantes em início de sílaba e início de vocábulo nos falantes da faixa etária mais velha. Como observamos na Tabela 3 , os dados referentes ao português falado pelos americanos mostram que os índices da retroflexa diminuem gradativamente, à medida que os estilos de linguagem se tornam mais formais - exceto na leitura da lista de palavras - e os do tepe e da glotal, ao contrário, aumentam - exceto também no estilo de leitura de lista de palavras (DUTRA, 2003).

O mesmo ocorre com os informantes espanhóis, ao pronunciarem a vibrante alveolar. Seus índices de uso são altos no estilo de fala informal apresentando uma queda em estilos mais formais. Os índices de uso do tepe diminuem à medida que a fala se torna mais formal. É relevante comentar que o que é mais marcante na língua nativa dos aprendizes do português das duas nacionalidades é justamente o que exerce influência sobre os informantes americanos quando usam a retroflexa e sobre os espanhóis quando pronunciam a vibrante alveolar.

Vemos que a retroflexa, a vibrante alveolar e o tepe aparecem em estilos nos quais os informantes, preocupados em se comunicar, não se preocupam sobre as estruturas das variantes que vão utilizar. Desse modo, nesse estilo de linguagem, usam, na língua-alvo, estruturas - no caso, a vibrante retroflexa, a vibrante alveolar e o tepe - que pertencem à sua língua materna. Já em estilos de fala mais formais, como o estilo de fala dirigido, a leitura de textos e da lista de palavras, os informantes buscam ajustar as estruturas de sua língua materna àquelas do português 
que estão aprendendo, realizando, em um estilo de fala mais refletido, fonemas da língua-alvo que acreditam ser usados naquele contexto - no caso, a glotal desvozeada.

Tabela 3. Uso das vibrantes, pelos informantes americanos e espanhóis nos quatro estilos de linguagem, em posição pré-vocálica em início de vocábulo

\begin{tabular}{|c|c|c|c|c|c|}
\hline & & \multicolumn{2}{|c|}{ Americanos } & \multicolumn{2}{|c|}{ Espanhóis } \\
\hline & & no & $\%$ & no & $\%$ \\
\hline \multirow{5}{*}{ 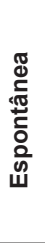 } & I & 13 & 68,42 & 0 & 0,00 \\
\hline & r & 2 & 10,53 & 0 & 0,00 \\
\hline & $\mathrm{h}$ & 4 & 21,05 & 7 & 30,43 \\
\hline & $\hat{\mathrm{r}}$ & 0 & 0,00 & 16 & 69,57 \\
\hline & Total & 19 & 100 & 23 & 100 \\
\hline \multirow{5}{*}{$\frac{\frac{\pi}{6}}{\frac{0}{3}}$} & 1 & 4 & 19,05 & 0 & 0,00 \\
\hline & $r$ & 3 & 14,28 & 1 & 1,02 \\
\hline & $\mathrm{h}$ & 14 & 66,67 & 24 & 24,49 \\
\hline & $\hat{r}$ & 0 & 0,00 & 73 & 74,49 \\
\hline & Total & 21 & 100 & 98 & 100 \\
\hline \multirow{5}{*}{ 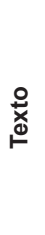 } & 1 & 2 & 11,11 & 0 & 0,00 \\
\hline & $r$ & 5 & 27,78 & 2 & 4,17 \\
\hline & $\mathrm{h}$ & 11 & 61,11 & 24 & 50,00 \\
\hline & $\hat{r}$ & 0 & 0,00 & 22 & 45,83 \\
\hline & Total & 18 & 100 & 48 & 100 \\
\hline \multirow{5}{*}{ 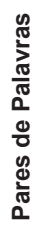 } & 1 & 4 & 25,00 & 0 & 0,00 \\
\hline & $r$ & 4 & 25,00 & 0 & 0,00 \\
\hline & $\mathrm{h}$ & 8 & 50,00 & 21 & 48,84 \\
\hline & $\hat{r}$ & 0 & 0,00 & 22 & 51,16 \\
\hline & Total & 16 & 100 & 43 & 100 \\
\hline
\end{tabular}

Esses resultados podem contribuir de modo significativo para o ensino aprendizagem do português como segunda língua, pois as interferências da língua materna identificadas na fala dos informantes das três faixas etárias, bem como as influências dos fatores linguísticos e extralinguísticos na aquisição do português como segunda língua, mostram que os professores de língua estrangeira precisam estar atentos aos fatores que podem interferir na aprendizagem dos alunos, a fim de identificar e reforçar estruturas ainda não assimiladas por alguns, procedendo de forma diferente daquela trabalhada com aqueles que já assimilaram tais estruturas.

\subsubsection{As vibrantes em grupos consonantais}

Segundo Cristófaro-Silva (2001), nos grupos consonantais da língua portuguesa nos quais a vibrante é a segunda consoante, realiza-se normalmente o tepe.
Porém, no português falado pelo grupo de americanos pesquisado, co-ocorrem, nessa estrutura silábica, as variantes: retroflexa, retrato [he'tıatu], e tepe, prata ['prata]. Em grupos consonantais - diferentemente do que acontece com as vibrantes em posição pré-vocálica em início de vocábulo, contexto em que a retroflexa só aparece na fala dos informantes da faixa etária mais velha - encontramos essa variação no uso das vibrantes em informantes das três faixas etárias, embora com o predomínio do tepe. Os resultados mostram redução gradual nos índices de ocorrência da retroflexa, da faixa etária mais velha para a mais jovem, e elevação, também gradual, dos índices do tepe, da faixa etária mais velha para a mais jovem (DUTRA, 2003). Já com os grupos de espanhóis verificamos somente o uso do tepe nessa estrutura (cf. Tab. 4).

Tabela 4. Uso das vibrantes, pelos informantes americanos e espanhóis das três faixas etárias, em grupos consonantais

\begin{tabular}{|c|c|c|c|c|c|c|}
\hline \multicolumn{7}{|c|}{ Americanos } \\
\hline & \multicolumn{2}{|c|}{ 1a Faixa etária } & \multicolumn{2}{|c|}{ 2- Faixa etária } & \multicolumn{2}{|c|}{ 3a faixa etária } \\
\hline & no & $\%$ & no & $\%$ & no & $\%$ \\
\hline 1 & 9 & 5,08 & 12 & 7,59 & 91 & 37,45 \\
\hline$r$ & 168 & 94,92 & 146 & 92,41 & 152 & 62,55 \\
\hline $\mathrm{h}$ & 0 & 0,00 & 0 & 0,00 & 0 & 0,00 \\
\hline$\hat{r}$ & 0 & 0,00 & 0 & 0,00 & 0 & 0,00 \\
\hline Total & 177 & 100 & 158 & 100 & 243 & 100 \\
\hline \multicolumn{7}{|c|}{ Espanhóis } \\
\hline & \multicolumn{2}{|c|}{ 1a Faixa etária } & \multicolumn{2}{|c|}{ 2- Faixa etária } & \multicolumn{2}{|c|}{ 3a faixa etária } \\
\hline & no & $\%$ & no & $\%$ & no & $\%$ \\
\hline 1 & 0 & 0,00 & 0 & 0,00 & 0 & 0,00 \\
\hline$r$ & 130 & 100 & 232 & 100 & 439 & 100 \\
\hline $\mathrm{h}$ & 0 & 0,00 & 0 & 0,00 & 0 & 0,00 \\
\hline$\hat{r}$ & 0 & 0,00 & 0 & 0,00 & 0 & 0,00 \\
\hline Total & 130 & 100 & 232 & 100 & 439 & 100 \\
\hline
\end{tabular}

Pelo fato de haver na língua espanhola o tepe nesse mesmo contexto, e não haver no sistema consonantal a variante retroflexa, os inquiridos dessa nacionalidade não apresentaram dificuldades para a realização dessa estrutura. Já com os informantes americanos vimos que no contexto de início de sílaba, em início de vocábulo, há o emprego da retroflexa e do tepe apenas entre os informantes da primeira faixa etária, o que indica a não-interferência da língua materna sobre os mais jovens. Já em grupos consonantais, a interferência da língua materna mostra-se mais marcante na fala dos aprendizes do português, pois, como vemos na Tabela 4, o uso da retroflexa mantém-se mesmo entre os informantes americanos da faixa etária mais jovem. 
Àquilo que vemos nesse contexto a Linguística contrastiva chama de interferência positiva ou negativa, ou seja, os aprendizes de língua estrangeira apresentam mais facilidade em assimilar estruturas que estão presentes em sua língua materna e dificuldades naquelas ausentes, o que requer do professor de línguas um trabalho diferenciado com os alunos aprendizes do português. Ele precisa estar atento às estruturas que causam dificuldades no aprendizado de segunda língua para poder averiguar os problemas que possam dificultar ou impedir a comunicação.

Os resultados obtidos com os americanos mediante a análise dos estilos de linguagem da primeira faixa etária indicam a mesma tendência apresentada por esse fenômeno em início de vocábulo, ou seja, à medida que os informantes falam mais refletidamente, há uma redução dos índices da retroflexa - exceto na leitura da lista de palavras - e elevação nos índices do tepe - exceto, também, na leitura da lista de palavras (cf. Tab. 5). Não analisamos o uso das vibrantes em grupos consonantais de acordo com os estilos de linguagem nas segunda e terceira faixas etárias, porque os resultados não se mostraram relevantes. Também não analisamos os estilos de linguagem dos espanhóis, pois, não havendo variação, não há motivo para analisar os estilos de linguagem.

Tabela 5. Uso das vibrantes, pelos informantes americanos da primeira faixa etária, nos quatro estilos de linguagem, em grupos consonantais

\begin{tabular}{lccc}
\hline \multirow{2}{*}{$\begin{array}{c}\text { Estilo de } \\
\text { linguagem }\end{array}$} & \multicolumn{2}{c}{ Articulação das vibrantes } & \multirow{2}{*}{ Total } \\
\cline { 2 - 3 } & Retroflexa & Tepe & \\
\hline Espontânea & $42(52,50 \%)$ & $38(47,50 \%)$ & $80(100 \%)$ \\
Dirigida & $28(32,94 \%)$ & $57(67,06 \%)$ & $85(100 \%)$ \\
Texto & $14(22,95 \%)$ & $47(77,05 \%)$ & $61(100 \%)$ \\
Lista de palavras & $8(27,59 \%)$ & $21(72,41 \%)$ & $29(100 \%)$ \\
\hline
\end{tabular}

\subsubsection{As vibrantes entre vogais}

Antes da análise do uso das vibrantes entre vogais pelos grupos de americanos e espanhóis pesquisados, é preciso considerar que, nesse contexto, as vibrantes constituem dois fonemas em língua portuguesa e na língua espanhola: as vibrantes simples e múltipla marcam diferença de significado, por exemplo, nas palavras caro ['karv] e carro ['kahu] em português e no espanhol caro ['karo] e carro ['kařo]. No entanto, como vimos em Dutra (2003), no português falado pelos informantes americanos, ocorrem as três variantes tanto quando se trata do fonema posterior - por exemplo, correio [ko'heyu] [ko'reyu] [ko'seyu] - como quando o fonema é a vibrante simples - por exemplo, cereja [se'reza] [se'ıeza] [se'heza]. Obviamente, se o fonema em questão é a vibrante posterior $/ \mathrm{h} /$, predomina a articulação posterior e, por outro lado, se o fonema for a vibrante simples / $\mathrm{r} /$, realiza-se predominantemente o tepe.

Isso não acontece com os informantes espanhóis, ou seja, embora ocorram também as três variantes nesse contexto, com o fonema /r/, o predomínio é da vibrante alveolar/řr/e não da posterior $/ \mathrm{h} /$. Já com o fonema /r/ não houve variação na fala dos espanhóis, houve a realização somente do tepe (cf. Tab. 6).

Tabela 6. Uso das vibrantes, pelos informantes americanos e espanhóis entre vogais com o fonema /r/ - caro ['karu]

\begin{tabular}{ccccc}
\hline & \multicolumn{2}{c}{ Americanos } & \multicolumn{2}{c}{ Espanhóis } \\
\hline$\lambda$ & no & \% & no & $\%$ \\
$r$ & 25 & 2,94 & 0 & 0,00 \\
$\mathrm{~h}$ & 824 & 96,83 & 949 & 100 \\
$\hat{r}$ & 2 & 0,23 & 0 & 0,00 \\
Total & 0 & 0,00 & 0 & 0,00 \\
\hline
\end{tabular}

Tabela 7. Uso das vibrantes, pelos informantes americanos e espanhóis entre vogais com o fonema /r/ - carro ['kahu]

\begin{tabular}{ccccc}
\hline & \multicolumn{2}{c}{ Americanos } & \multicolumn{2}{c}{ Espanhóis } \\
\hline $\boldsymbol{N}$ & $\mathbf{n} \mathbf{\%}$ & \% & no & \% \\
\hline$r$ & 11 & 5,64 & 0 & 0,00 \\
$\mathrm{~h}$ & 13 & 6,67 & 2 & 0,67 \\
$\hat{r}$ & 171 & 87,69 & 79 & 26,33 \\
Total & 0 & 0,00 & 219 & 73,00 \\
\hline
\end{tabular}

Embora haja dois fonemas vibrantes na posição intervocálica na língua portuguesa, poucas vezes a substituição da realização do tepe por uma articulação posterior resulta em outra palavra, como, por exemplo, aranha [a'rãna] e arranha [a'hãna]. Desse modo, é remoto o risco de criar homonímias por meio do uso equivocado das vibrantes em contexto intervocálico. Na maioria das vezes, as mudanças na articulação das vibrantes, como depreendemos na fala dos grupos estudados, soam estranhas aos ouvidos dos falantes nativos do português brasileiro, sem, no entanto, alterar o significado do vocábulo pronunciado.

Segundo Dutra (2003), os dados referentes ao grupo americano mostram que as variantes retroflexa e tepe têm os índices reduzidos gradualmente nas faixas etárias mais jovens. Já os índices da glotal, ao contrário, têm-se elevado. O mesmo ocorre com os informantes espanhóis. Não há registro da consoante retroflexa, mas, à medida que a faixa etária se torna mais velha, eleva-se também o uso da vibrante alveolar na fala dos informantes espanhóis. A vibrante alveolar também apresenta índices elevados nas 
faixas etárias mais velhas, o que pode ser indício de que os informantes mais jovens adquiriram a vibrante norteparanaense mais facilmente, nesse contexto (cf. Tab. 8).

Tabela 8. Uso das vibrantes entre vogais, pelos informantes americanos e espanhóis das três faixas etárias, com o fonema /r/ - carro ['kahu]

\begin{tabular}{|c|c|c|c|c|c|c|}
\hline \multicolumn{7}{|c|}{ Americanos } \\
\hline & \multicolumn{2}{|c|}{ 1a Faixa etária } & \multicolumn{2}{|c|}{ 2a Faixa etária } & \multicolumn{2}{|c|}{ 3a faixa etária } \\
\hline & no & $\%$ & no & $\%$ & no & $\%$ \\
\hline$\perp$ & 0 & 0,00 & 1 & 2,04 & 10 & 13,70 \\
\hline$r$ & 2 & 2,74 & 2 & 4,08 & 9 & 12,33 \\
\hline $\mathrm{h}$ & 71 & 97,26 & 46 & 93,88 & 54 & 73,97 \\
\hline$\hat{r}$ & 0 & 0,00 & 0 & 0,00 & 0 & 0,00 \\
\hline Total & 73 & 100 & 49 & 100 & 73 & 100 \\
\hline \multicolumn{7}{|c|}{ Espanhóis } \\
\hline & \multicolumn{2}{|c|}{ 1a Faixa etária } & \multicolumn{2}{|c|}{ 2ª Faixa etária } & \multicolumn{2}{|c|}{ 3a faixa etária } \\
\hline & no & $\%$ & no & $\%$ & no & $\%$ \\
\hline$\lrcorner$ & 0 & 0,00 & 0 & 0,00 & 0 & 0,00 \\
\hline$r$ & 0 & 0,00 & 2 & 2,66 & 0 & 0,00 \\
\hline $\mathrm{h}$ & 71 & 100 & 8 & 10,67 & 0 & 0,00 \\
\hline$\hat{r}$ & 0 & 0,00 & 65 & 86,67 & 154 & 100 \\
\hline Total & 71 & 100 & 75 & 100 & 154 & 100 \\
\hline
\end{tabular}

Não analisamos o uso das vibrantes de acordo com os estilos de linguagem, porque os resultados não apresentaram regularidade nesse contexto. No contexto intervocálico, os índices indicam que a idade dos informantes é um fator determinante. Os falantes reduzem os índices da retroflexa e da posterior e elevam os índices do tepe nas faixas etárias mais jovens (cf. Tab. 9).

Tabela 9. Uso das vibrantes entre vogais, pelos informantes americanos e espanhóis das três faixas etárias, com o fonema /R/ - caro ['karu]

\begin{tabular}{|c|c|c|c|c|c|c|}
\hline \multicolumn{7}{|c|}{ Americanos } \\
\hline & \multicolumn{2}{|c|}{ 1a Faixa etária } & \multicolumn{2}{|c|}{ 2a Faixa etária } & \multicolumn{2}{|c|}{ 3a faixa etária } \\
\hline & no & $\%$ & no & $\%$ & no & $\%$ \\
\hline 1 & 3 & 1,29 & 2 & 0,80 & 20 & 5,44 \\
\hline r & 230 & 98,71 & 248 & 99,20 & 346 & 94,02 \\
\hline $\mathrm{h}$ & 0 & 0,00 & 0 & 0,00 & 2 & 0,54 \\
\hline$\hat{r}$ & 0 & 0,00 & 0 & 0,00 & 0 & 0,00 \\
\hline Total & 233 & 100 & 250 & 100 & 368 & 100 \\
\hline \multicolumn{7}{|c|}{ Espanhóis } \\
\hline & \multicolumn{2}{|c|}{ 1a Faixa etária } & \multicolumn{2}{|c|}{ 2- Faixa etária } & \multicolumn{2}{|c|}{ 3a faixa etária } \\
\hline & no & $\%$ & no & $\%$ & no & $\%$ \\
\hline 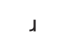 & 0 & 0,00 & 0 & 0,00 & 0 & 0,00 \\
\hline$r$ & 220 & 100 & 244 & 100 & 485 & 100 \\
\hline $\mathrm{h}$ & 0 & 0,00 & 0 & 0,00 & 0 & 0,00 \\
\hline$\hat{\imath}$ & 0 & 0,00 & 0 & 0,00 & 0 & 0,00 \\
\hline Total & 220 & 100 & 244 & 100 & 485 & 100 \\
\hline
\end{tabular}

Em cada um dos fonemas vibrantes $/ \mathrm{r} / \mathrm{e} / \mathrm{r} /$ há uma dada realização, e os falantes excluem aquela que representa a articulação do outro fonema: o fonema / $/$ / inibe a variante posterior que constitui realização fonética do fonema $/ \mathrm{r} /$. Registramos, na Tabela 6 , na fala dos americanos, apenas 2 realizações da variante glotal em um universo de 851 ocorrências de vibrantes referentes ao fonema $/ \mathrm{r} /$. O fonema $/ \mathrm{r} /$ também inibe a variante tepe que constitui realização fonética do fonema $/ \mathrm{r} /$.

Observamos, na Tabela 7, que de 195 ocorrências de vibrantes referentes ao fonema $/ \mathrm{r} /$ na fala dos americanos, somente em 13 vezes realiza-se o tepe. No entanto, percebemos que esse contexto leva os falantes à incerteza na realização dessas consoantes. Embora na maioria das vezes as variantes glotal e tepe tenham sido realizadas pelos americanos tal como ocorre no português, observamos que, durante a leitura de texto e da lista de palavras, alguns informantes não sabiam qual variante empregar nesse contexto. Registramos na fala desses aprendizes o tepe, a retroflexa e a glotal - até encontrarem a variante que, para eles, era a mais adequada.

Muitas vezes, alguns desses informantes pronunciavam a vibrante e olhavam para a entrevistadora com o intuito de receber um aceno de afirmação sobre a variante escolhida durante a leitura. Isso mostra que é forte, nesse contexto, a interferência da língua materna na aprendizagem do português. Desse modo, o professor de línguas precisa verificar se os alunos conhecem os fonemas e em quais estruturas eles podem ser empregados para que não haja incerteza ou uso equivocado de estruturas que estão sendo aprendidas.

Os dados mostram que os informantes espanhóis não variaram o som das vibrantes na posição intervocálica ao pronunciarem o fonema / / - caro ['karv] e sim, o fonema /r/ - carro ['kahu] ['kar̂u] ['karu]. De 300 ocorrências observadas na fala dos espanhóis, 219 foram da vibrante alveolar, apenas 79 da glotal e 2 do tepe (cf. Tab. 7). Vemos, então, que os espanhóis trazem para o português, nesse contexto, estruturas de sua língua materna, o que não ocorre no contexto onde há o fonema / $/$ /. Acreditamos que isso se deve ao fato dessa estrutura estar muito presente na língua materna desses informantes.

\subsubsection{As vibrantes em final de sílaba}

Como vimos em Dutra (2003) as vibrantes apresentam várias realizações fonéticas em travamento silábico na língua portuguesa. Se, por um lado, não há distinção fonológica entre diferentes articulações nessa estrutura silábica, por outro tais articulações marcam variedades dialetais, regionais no português brasileiro e diferenças entre grupos sociais. No falar norte-paranaense, predomina a realização retroflexa da vibrante em posição 
final de sílaba, articulação esta predominante também no português falado pelo grupo de americanos pesquisado - mar ['ma.I]. Diferentemente do que ocorre com o grupo espanhol. Em final de sílaba não é a retroflexa que predomina entre os informantes da pesquisa e sim o tepe - mar ['mar].

Na Tabela 10, no corpus referente a esse grupo, realizam-se as variantes: retroflexa, glotal e tepe. Não há registro da vibrante múltipla. Na fala dos espanhóis aparecem as vibrantes: retroflexa, glotal, vibrante alveolar e tepe. Não consideramos, em nossa análise, a apócope da vibrante que ocorre frequentemente em final de palavra, pois, para levá-la em conta, precisaríamos de uma investigação sobre o seu condicionamento morfossintático, o que não constitui o objetivo desta pesquisa.

Tabela 10. Uso das vibrantes em final de sílaba (geral)

\begin{tabular}{ccccc}
\hline & \multicolumn{2}{c}{ Americanos } & \multicolumn{2}{c}{ Espanhóis } \\
\cline { 2 - 5 } & no & \% & no & $\%$ \\
\hline$r$ & 740 & 94,63 & 240 & 25,67 \\
h & 16 & 2,05 & 576 & 61,60 \\
$\hat{r}$ & 26 & 3,32 & 2 & 0,22 \\
Total & 0 & 0,00 & 117 & 12,51 \\
\hline
\end{tabular}

Como afirma Dutra (2003), os dados contidos na tab. 10 referentes aos americanos indicam que o uso da vibrante em final de sílaba pelo grupo de americanos tem características muito semelhantes ao que observamos no falar norte paranaense, no qual registramos uma frequência muito alta da variante retroflexa, aparecendo esporadicamente as pronúncias glotal e tepe nas três faixas etárias. Embora haja a realização das quatro variantes na fala dos grupos de espanhóis, a frequência mais alta nesse contexto ocorre com a variante tepe, seguida da retroflexa e, por fim, há também a realização da vibrante alveolar.

Como vemos na Tabela 11, os informantes americanos mais jovens e os mais velhos empregam a variante regional /.I/ em final de sílaba, embora apresentem variação com o tepe e a glotal. Já os informantes espanhóis mais jovens empregam quase categoricamente a retroflexa, embora os mais velhos apresentem maior índice do tepe nesse contexto. Acreditamos que o motivo que leva os informantes espanhóis a empregarem o tepe nesse contexto é, primeiramente, o desejo de não diferir tanto de sua língua materna e, ao mesmo tempo, evitar o uso da retroflexa. Na verdade, essa variedade norte-paranaense é sociolinguisticamente marcada como não atrativa para pessoas que vêm de fora, não somente do exterior, mas de outras regiões do Brasil.
Tabela 11. Uso das vibrantes, pelos informantes americanos e espanhóis das três faixas etárias, em final de sílab

\begin{tabular}{|c|c|c|c|c|c|c|}
\hline \multicolumn{7}{|c|}{ Americanos } \\
\hline & \multicolumn{2}{|c|}{ 1a Faixa etária } & \multicolumn{2}{|c|}{ 2a Faixa etária } & \multicolumn{2}{|c|}{ 3a faixa etária } \\
\hline & no & $\%$ & no & $\%$ & no & $\%$ \\
\hline$\lambda$ & 730 & 96,17 & 137 & 96,48 & 322 & 94,15 \\
\hline$r$ & 3 & 0,40 & 0 & 0,00 & 3 & 0,88 \\
\hline $\mathrm{h}$ & 26 & 3,43 & 5 & 3,52 & 17 & 4,97 \\
\hline$\hat{r}$ & 0 & 0,00 & 0 & 0,00 & 0 & 0,00 \\
\hline Total & 759 & 100 & 142 & 100 & 342 & 100 \\
\hline \multicolumn{7}{|c|}{ Espanhóis } \\
\hline & \multicolumn{2}{|c|}{ 1a Faixa etária } & \multicolumn{2}{|c|}{ 2- Faixa etária } & \multicolumn{2}{|c|}{ 3a faixa etária } \\
\hline & no & $\%$ & no & $\%$ & no & $\%$ \\
\hline 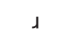 & 227 & 98,26 & 2 & 0,69 & 11 & 2,65 \\
\hline$r$ & 2 & 0,87 & 237 & 82,01 & 337 & 81,20 \\
\hline $\mathrm{h}$ & 2 & 0,87 & 0 & 0,00 & 0 & 0,00 \\
\hline$\hat{\imath}$ & 0 & 0,00 & 50 & 17,30 & 67 & 16,15 \\
\hline Total & 231 & 100 & 289 & 100 & 415 & 100 \\
\hline
\end{tabular}

Tabela 12. Uso das vibrantes, pelos informantes americanos e espanhóis das três faixas etárias, nos quatro estilos de linguagem, em final sílaba

\begin{tabular}{|c|c|c|c|c|c|}
\hline & \multicolumn{2}{|c|}{ Americanos } & \multicolumn{2}{|c|}{ Espanhóis } \\
\hline & & no & $\%$ & no & $\%$ \\
\hline \multirow{5}{*}{ 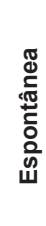 } & 1 & 174 & 95,60 & 20 & 9,22 \\
\hline & $r$ & 7 & 3,85 & 185 & 85,25 \\
\hline & $\mathrm{h}$ & 1 & 0,55 & 0 & 0,00 \\
\hline & $\hat{r}$ & 0 & 0,00 & 12 & 5,53 \\
\hline & Total & 182 & 100 & 217 & 100 \\
\hline \multirow{5}{*}{ 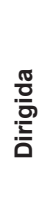 } & \lrcorner & 221 & 94,44 & 86 & 23,12 \\
\hline & $r$ & 6 & 2,57 & 242 & 65,05 \\
\hline & $\mathrm{h}$ & 7 & 2,99 & 1 & 0,27 \\
\hline & $\hat{r}$ & 0 & 0,00 & 43 & 11,56 \\
\hline & Total & 234 & 100 & 372 & 100 \\
\hline \multirow{5}{*}{ 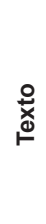 } & 1 & 194 & 92,82 & 71 & 40,11 \\
\hline & $r$ & 1 & 0,48 & 97 & 54,80 \\
\hline & $\mathrm{h}$ & 14 & 6,70 & 0 & 0,00 \\
\hline & $\hat{r}$ & 0 & 0,00 & 9 & 5,09 \\
\hline & Total & 157 & 100 & 169 & 100 \\
\hline \multirow{5}{*}{ 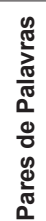 } & \lrcorner & 151 & 96,18 & 63 & 37,28 \\
\hline & $r$ & 2 & 1,27 & 52 & 30,77 \\
\hline & $\mathrm{h}$ & 4 & 2,55 & 1 & 0,59 \\
\hline & $\hat{r}$ & 0 & 0,00 & 53 & 31,36 \\
\hline & Total & 157 & 100 & 169 & 100 \\
\hline
\end{tabular}

Os dados referentes às vibrantes em final de sílaba, de acordo com os estilos de linguagem (cf. Tab. 12), mostram que os índices da retroflexa na fala dos americanos são elevados desde o contexto espontâneo ao mais formal, apresentando poucas ocorrências do tepe e da glotal 
(DUTRA, 2003). Com o grupo de espanhóis vemos que, conforme os estilos se tornam mais formais, os índices da retroflexa aumentam e os do tepe diminuem - exceto em pares de palavras. Acreditamos que os informantes empregam a retroflexa sempre que se encontram em um estilo mais refletido de fala.

\section{Considerações finais}

A análise dos dados levantados referentes às vibrantes permite que sejam feitas algumas observações. Primeiramente, vemos que os grupos de americanos e espanhóis apresentam variação no uso das vibrantes em praticamente todos os contextos - exceto em grupos consonantais e em posição intervocálica com a vibrante simples / / / em que não houve variação na fala dos espanhóis. Essa variação é influenciada por uma diversidade de fatores linguísticos e extralinguísticos que podem tanto favorecer quanto inibir o processo de aprendizagem. $\mathrm{O}$ contexto em que se usa o fonema no inglês e no espanhol motiva o seu uso no português: por exemplo, o uso da retroflexa em início de sílaba, em início de vocábulo pelos informantes americanos - redondo [ıe'dõdu] - e em grupos consonantais - prova ['pıəva], o uso da vibrante alveolar do espanhol em trava silábica carta ['kârto] e em início de sílaba rato [r̂atu].

Assim como vimos na análise do português falado pelos americanos, percebemos que o mesmo ocorre na fala dos espanhóis cujos fatores extralinguísticos, como a idade dos informantes e os estilos de linguagem, também devem ser considerados no ensino e aprendizagem do português como segunda língua. Observamos no início de sílaba o predomínio da retroflexa na fala dos americanos e da luta entre a vibrante alveolar e a glotal na fala dos espanhóis.

A variação no uso das vibrantes nesse contexto ocorre entre os informantes mais velhos que apresentam mais dificuldades em se desvencilhar de estruturas da língua nativa, diferentemente do que ocorre entre os informantes mais jovens, cuja adaptação às características da língua-alvo é mais fácil. Já em grupos consonantais, os resultados mostraram variação na fala dos americanos, o que não ocorreu na fala dos espanhóis. Na posição intervocálica com o fonema $/ \mathrm{r} /$, diferentemente do que ocorreu com os americanos, onde houve o predomínio da glotal, os espanhóis empregaram predominantemente a vibrante alveolar.
Os dados sobre as vibrantes permitem-nos concluir que o fator extralinguístico idade é importante, pois em faixas etárias mais velhas, são altos os índices de uso da vibrante alveolar pelos espanhóis e da retroflexa pelos americanos em posição intervocálica, e em posição pré-vocálica referentes ao fonema / /̂े/pelos espanhóis. Em final de sílaba, os resultados mostram uma diferença no emprego das vibrantes entre os americanos e espanhóis. Da mesma forma que o uso da retroflexa é praticamente categórico na fala dos americanos, na fala dos espanhóis prevalece o tepe, sobretudo em estilos mais formais. Embora constatemos que, conforme os estilos se tornam mais formais, aumentam os índices da retroflexa para ficarem mais próximos à variante falada na região.

Essas constatações levam-nos a pensar no ensino do português para estrangeiros sob outro prisma, com tantos estrangeiros migrando para o Brasil para se estabelecer, para estudar, trabalhar, enfim, por diversos motivos e, também, com tantos estudos realizados que buscam entender a aquisição do português falado por estes estrangeiros, há a necessidade de se desenvolver técnicas e metodologias que tornem essa aquisição mais satisfatória.

\section{Referências}

BROSELOW, Ellen. Uma investigação sobre transferência em fonologia de segunda língua. IRAL, v. XXII, n. 4, nov. 1984.

CONFORTIN, Helena. Atitudes linguísticas de falantes bilíngues. Letras, PUC-Campinas, v. 20, n. 1/2, p. 123-135, dez. 2001

CRISTÓFARO-SILVA, Thaïs. Fonética e fonologia do Português: roteiro de estudo e guia de exercícios. São Paulo: Contexto, 2001.

DUTRA, Alessandra. Fenômenos de variação na aquisição do português como segunda língua. 2003. 124 f. Dissertação (Mestrado em Estudos da Linguagem) - Universidade Estadual de Londrina, Londrina, 2003.

FERNÁNDEZ, Francisco Moreno. Princípios de sociolingüística y sociologia del lenguaje. Barcelona: Ariel, 1998.

LABOV, William. Sociolinguistic patterns. Philadelphia: University of Pennsylvania Press, 1972.

LARSEN-FREEMAN, Diane; LONG, Michael H. An introduction to second Language Acquisition Research. Londres: Longman, 1993.

Recebido: 16 de agosto de 2016

Aprovado: 10 de março de 2017

Contato: alessandradutra@yahoo.com.br 